\title{
Towards industrial furfural conversion: selectivity and stability of palladium and platinum catalysts under continuous flow regime
}

Weiyi Ouyang ${ }^{\mathrm{a},{ }^{*}}$, Alfonso Yepez ${ }^{\mathrm{a}}$, Antonio A. Romero ${ }^{\mathrm{a}}$, and Rafael Luque ${ }^{\mathrm{a},{ }^{*}}$

${ }^{a}$ Departamento de Quimica Organica, Universidad de Cordoba, Campus de Rabanales, Edificio Marie Curie, CtraNnal IV, Km. 396, E-14014, Cordoba, Spain

*Correspondence to: qo2ououw@uco.es (W. Ouyang); q62alsor@uco.es (R. Luque)

\begin{abstract}
Furfural is an important biorefinery platform chemical, derived from hemicelluloses which represent an import fraction of lignocellulosic biomass feedstocks and waste streams originating from them. Recently, promising results have been reported on the hydrogenation of furfural, although the selectivity still may be improved. Most of these studies dealt with batch hydrogenation, however, hydrogenation in continuous flow is preferable for industrial applications. In this work, we compare the conversion, selectivity and stability on-stream in continuous flow regime of lab-synthesized and commercial palladium and platinum catalysts.
\end{abstract}

Keywords: Furfural; Hydrogenation; Continuous Flow; Selectivity; Stability

\section{INTRODUCTION}

The global population could reach and even exceed 9 billion by 2050 [1]. The use of sustainable feedstocks to meet the growing global energy demand and to reduce the use of fossil resources is now a highly imminent challenge for the research community, and a 
challenge to be adopted in currently existing industrial refineries or to be designed in future biorefinery plants. The largest part of the current fossil derived petroleum refining is used for fuels production. Still, an important part of petroleum is used for the production of bulk chemicals and materials. Today, the use of alternative biomass feedstocks (or waste streams derived from them) has become a widely reported research area. Considering the complexity and the recalcitrance of biomass, many works focused on the transformation of biomass derived platform molecules to fuels and high-added value chemicals. For example, C5 sugars are key representative compounds of the hemicellulose fraction of lignocellulose, which can be converted to valuable platform molecules and subsequently valorized into high-added value products [2]. Furfural (F) is an important platform chemical, which can be obtained via dehydration under mild conditions from xylose, a typical C5 sugar.

Furfural can undergo reactions typical for aldehydes like acetalization, acylation, aldol and Knoevenagel condensations, reduction to alcohols, reductive amination to amines, decarbonylation, oxidation to carboxylic acids and Grignard reactions. Besides, the furan ring can be subjected to alkylation, hydrogenation, oxidation, halogenations and nitration reactions. Due to the electron-withdrawing effect of the carbonyl group, the furan ring is less susceptible to hydrolytic ring cleavage and Diels-Alder cycloaddition reactions. Therefore, furfural is considered to be an attractive platform chemical for the production of a wide range of chemicals, e.g. solvents (tetrahydrofuran), plastics (in particular, polyamides), resins via furfuryl alcohol and fuel additives (methylfuran, methyltetrahydrofuran, valerate esters, ethylfurfuryl and ethyltetrahydrofurfuryl ethers and C10C15 coupling products) [2]. Around 60-70 \% of the global furfural production is converted to furfuryl alcohol $[2,3]$. It is widely reported that furfural can be further transformed into 
various compounds by hydrogenation, such as furfuryl alcohol (FA), tetrahydrofurfuryl alcohol (THFA), 2-methylfuran (MF) and 2-methyltetrahydrofuran (MTHF). Most of these reactions were performed in batch conditions [4-8] with noble or transition metals based catalysts, while only a few of them were performed in continuous flow [7,9]. Especially, these reactions were performed using only either lab-synthesized or commercial catalysts, with a simple comparison of existing results obtained under different conditions. Regarding to the advantages of flow chemistry, such as faster, safer reactions and easy scale-up, it would be interesting to give a comparison of catalytic performance of both lab-synthesized and commercial catalysts under same reaction conditions in continuous flow system. Previous work from our group has provided insights into the reaction pathway comparing noble metal and transition metal catalysts (Scheme 1), showing favorable results for Pd based catalysts [9]. The mechanism of furfural conversion on palladium catalysts was also studied by other researchers based on density functional theory (DFT) [10].

Despite the excellent conversion and selectivity of Pd catalysts, adding magnetic properties to the catalyst would be preferable for catalyst recovery through applying an external magnetic field, which would result in a more straightforward and cost-effective separation method as compared with conventional methods, as illustrated in previous reports [11-14]. Magnetically separable Pd based nanocomposite materials have shown good catalytic activities before in different organic synthesis, such as oxidation and C-C coupling [15-18]. Interestingly, temperature and pressure were reported to have significant positive effects to the reaction [19]. In previous work in our group on continuous flow furfural hydrogenation with hydrogen gas, relatively mild conditions were used $\left(90^{\circ} \mathrm{C}, 50\right.$ bar, $0.3 \mathrm{~mL} \mathrm{~min}^{-1}$ ) [9]. In continuation of our previous work, we employ a lower catalyst 
loading, but at higher temperature and longer residence time, using both lab-synthesized and commercial catalysts to provide a comparison in terms of activity and stability. This study on hydroconversion of furfural attempts to further progress towards the industrial valorization of hemicellulose derived compounds in lignocellulosic biomass.

\section{EXPERIMENTAL}

\subsection{Reagents}

Chemicals were purchased from Sigma-Aldrich [Pluronic P123, tetraethyl orthosilicate, palladium (II) acetate, tetraammineplatinum (II) chloride hydrate, iron nitrate nanohydrate, furfural, furfuryl alcohol, tetrahydrofurfuryl alcohol, aluminum isopropoxide], Panreac [37\% $\mathrm{HCl}$, ethanol] and Merk [ $\left.\mathrm{Fe}\left(\mathrm{NO}_{3}\right)_{3}{ }^{*} \mathrm{H}_{2} \mathrm{O}\right]$ respectively. All chemicals were used as purchased in the experiments without any further purification.

\subsection{Synthesis of SBA-15 and Al-SBA15}

SBA-15 silica was prepared according to the procedure reported by Bonardet et al [20]. More specific, Pluronic P123 surfactant (8.0 g) was dissolved into a solution of deionized water $(260 \mathrm{~mL})$ and $\mathrm{HCl}(12 \mathrm{M}, 40 \mathrm{~mL})$ under vigorous stirring at $40{ }^{\circ} \mathrm{C}$ for $2 \mathrm{~h}$. Subsequently, $7 \mathrm{~g}$ of tetraethyl orthosilicate (TEOS) were added dropwise to the above solution. The mixture was stirred at $40{ }^{\circ} \mathrm{C}$ for $24 \mathrm{~h}$, followed by hydrothermal treatment at $100{ }^{\circ} \mathrm{C}$ for $48 \mathrm{~h}$ in an oven. The liquid phase was removed by filtration and the obtained white solid was dried at $60{ }^{\circ} \mathrm{C}$. The template was removed by calcination at $600{ }^{\circ} \mathrm{C}$ for 8 h. The Al-SBA support was synthesized using a modification of the protocol previously reported by our group [21]. After filtration and drying dried at RT, the solid was calcined under nitrogen atmosphere at $600^{\circ} \mathrm{C}$ for $2 \mathrm{~h}$ and then in air for an additional $6 \mathrm{~h}$.

\subsection{Synthesis of $\mathrm{Cu}-\mathrm{Pd} / \mathrm{Al}-\mathrm{SBA}-15$}


The continuous flow deposition of palladium oxide nanoparticles on Al-SBA-15 was performed under a series of conditions using a recently reported innovative continuous setup [22]. A stainless-steel reactor was packed with Al-SBA-15 support set between two plugs of quartz wool to prevent the solid support to move in the reactor upon pumping in the flow of the metal precursor feed solution. Separately, a $0.5 \mathrm{wt} \%$ Pd solution in ethanol was prepared using palladium (II) acetate as Pd precursor. The solution was filtered off prior to flow through the system to avoid the presence of any undissolved metal precursor. The system started with pumping a solution of pure ethanol $\left(0.5 \mathrm{~mL} \mathrm{~min}^{-1}, 5 \mathrm{~min}\right)$ through the catalyst bed to wet the support. The temperature of the reactor was then set to $150{ }^{\circ} \mathrm{C}$ and the feed was changed to the $0.5 \mathrm{wt} \%$ Pd solution. The incorporation was conducted under optimized flow rates $\left(0.5 \mathrm{~mL} \mathrm{~min}^{-1}\right)$ and circulation time $(15 \mathrm{~min}$.). At the end of the process, the feed was again switched to ethanol which was pumped through the Pdincorporated catalyst to remove physisorbed/unreacted Pd species on the catalyst. The resulting Pd/Al-SBA-15 was recovered from the reactor and calcined at $400{ }^{\circ} \mathrm{C}$ for $4 \mathrm{~h}$ under air. Following, the $\mathrm{Cu}$ nanoparticles were supported on Pd/Al-SBA-15 material by a mechanochemical protocol using a planetary ball mill (Retsch 100) under previously reported optimized conditions (350 rpm, $10 \mathrm{~min}$ ) [23] yielding the $\mathrm{Cu}-\mathrm{Pd} / \mathrm{Al}-\mathrm{SBA}-15$ bimetallic catalyst after calcination at $400{ }^{\circ} \mathrm{C}$ for $4 \mathrm{~h}$ in air.

\subsection{Synthesis of $(\mathrm{Pd}, \mathrm{Pt}) / \mathrm{SBA}-15$}

Pd/SBA-15 and Pt/SBA-15 materials were synthesized following a previously reported mechanochemical protocol for the straightforward preparation of the supported metal nanoparticles on SBA-aluminosilicates [23]. The appropriate amount of $\mathrm{Pd}$ and $\mathrm{Pt}$

precursor (palladium (II) acetate and tetraammineplatinum (II) chloride hydrate, 
respectively) to reach the theoretical Pd and Pt contents of $2 \mathrm{wt} \% \mathrm{Pd}$ and Pt, respectively. The pattern SBA-15 and precursor were milled together in a planetary ball mill (Retsch 100) under previously reported optimized conditions (350 rpm, $10 \mathrm{~min}$ ) [23]. Upon incorporation of the metal, the sample was calcined at $400{ }^{\circ} \mathrm{C}(4 \mathrm{~h}$, in air). The obtained materials were highly reproducible from batch to batch.

\subsection{Synthesis of Pd/MAGSNC}

5\% Pd/MAGSNC was synthesized using a mechanochemical method according to the protocol reported previously by our group [24]. In detail, $0.5 \mathrm{~g}$ synthesized SBA-15 was grinded with $1.34 \mathrm{~g} \mathrm{Fe}\left(\mathrm{NO}_{3}\right)_{3} \cdot 9 \mathrm{H}_{2} \mathrm{O}, 0.25 \mathrm{~mL}$ propionic acid and an appropriate amount of the palladium precursor $\left[\mathrm{Pd}(\mathrm{Ac})_{2}\right]$ in a Retsch PM-100 planetary ball mill $(1810 \mathrm{~mm}$ stainless steel balls, $10 \mathrm{~min}, 350 \mathrm{rpm}$ ) to reach a theoretical $5 \mathrm{wt} \% \mathrm{Pd}$ loading. The nanocomposite was slowly heated $\left(1{ }^{\circ} \mathrm{C} \mathrm{min}{ }^{-1}\right)$ to $300{ }^{\circ} \mathrm{C}$ under air and kept at $300{ }^{\circ} \mathrm{C}$ for an additional $30 \mathrm{~min}$.

\subsection{Continuous flow hydrogenation}

The hydrogenation of furfural was performed in a H-Cube Pro apparatus (ThalesNano, see Figure S1 in the supporting information (SI)). Both lab-synthesized and commercial catalysts ( $c a .100 \mathrm{mg}$ ) were packed in CatCart cartridges, a stainless-steel tube with length of $70 \mathrm{~mm}$ and inner diameter $4 \mathrm{~mm}$. The synthesized SBA catalysts based were swollen upon absorbing solvent; therefore, the SBA supported catalysts were first diluted with celite at 1:1 mass ratio prior to package. A feedstock solution of $0.2 \mathrm{M}$ furfural in ethyl acetate (EA) was prepared as starting material. A filter was applied in the entrance of the pump to avoid undissolved compounds entering to the system. Prior to catalytic conversion experiments, EA was pumped through the continuous flow system. When reaching the 
desired reaction conditions in the reaction column (temperature, pressure and flow rate), the EA solvent feed was substituted by a $0.2 \mathrm{M}$ furfural solution in EA. The flow rate and the hydrodynamic system pressure were set as $0.3 \mathrm{~mL} \mathrm{~min}^{-1}$ and 50 bar, identically as in the work reported previously reported by our group [9]. Full hydrogen mode was used in each reaction, which corresponds to a hydrogen production capacity of $60 \mathrm{~mL} / \mathrm{min}$ in the H-Cube pro. The reactions took place upon contact of the catalyst with the mixture of feed solution and hydrogen in the CatCart column. After pumping the $0.2 \mathrm{M}$ furfural feed, samples were taken from the product flow in the outlet at different time intervals. The timeon-stream was measured with the zero point at the moment that experimental reaction conditions were reached and after changing the feed from EA solvent to furfural solution in EA. The weight hourly space velocity (WHSV) was calculated by dividing the mass flow rate of the reagent with the catalyst mass. With the above described reaction conditions and catalyst loading, WHSV in the current work were between $3.3-4.6 \mathrm{~h}^{-1}$. The WSHV values on metal weight basis were between 38 and $865 \mathrm{~h}^{-1}$.

\subsection{Product analysis and calculations}

The product solution was analyzed by GC. Calibration curves (Figure S2, see SI) were determined for furfural $(\mathrm{F})$ and the two main products, furfuryl alcohol (FA) and tetrahydrofurfuryl alcohol (THFA). The other products, 2-methylfuran and/or pentenol, were only detected as traces. The calibration solutions and all collected samples were analyzed in an Agilent 6850 series II gas chromatograph combined with an Agilent 5975C VL MSD system fitted with an HP-5MS-UI column $(30 \mathrm{~m} \times 0.25 \mathrm{~mm} \times 0.25 \mu \mathrm{m}$ i.d. $)$. He in constant flow rate mode was used as carrier gas, which starting pressure was 0.88 bar. The initial temperature was $50^{\circ} \mathrm{C}$ with $3 \mathrm{~min}$. hold time, then the temperature ramped to 
$200{ }^{\circ} \mathrm{C}$ in $3 \mathrm{~min}$. and stayed at $200{ }^{\circ} \mathrm{C}$ for another $3 \mathrm{~min}$. Finally, the temperature was increased to $300{ }^{\circ} \mathrm{C}$ at $100{ }^{\circ} \mathrm{C} \min ^{-1}$ and held at $300{ }^{\circ} \mathrm{C}$ for $2 \mathrm{~min}$. The conversion and selectivity were calculated as the following:

$$
\begin{gathered}
\text { Furfural conversion }(\%)=\frac{\left[C_{\text {Initial }}-C_{\text {Final }}\right]}{C_{\text {Initial }}} \times 100 \\
\text { Selectivity }(\%)=\frac{C_{\text {Product }}}{\left[C_{F(\text { Initial })}-C_{F(\text { Final })}\right]}
\end{gathered}
$$

Where $\mathrm{C}$ is the concentration of furfural or product $\left(\mathrm{mmol} \mathrm{mL}^{-1}\right)$ as determined by GC.

\subsection{Catalyst characterization}

A VG Scientific photoelectron spectrometer ESCALAB-210 equipped with $\mathrm{Mg} \mathrm{K} \alpha$ radiation $(1486.6 \mathrm{eV})$ from an $\mathrm{X}$-ray source was applied for the $\mathrm{X}$-ray photoelectron spectroscopy (XPS) measurements, operated at $15 \mathrm{kV}$ and $20 \mathrm{~mA}$. Survey spectra in the energy range from 0 to $1350 \mathrm{eV}$ were recorded using $0.4 \mathrm{eV}$ steps for all the samples. High resolution spectra were recorded with $0.1 \mathrm{eV}$ steps, $100 \mathrm{~ms}$ dwell time and $25 \mathrm{eV}$ pass energy. A $90^{\circ}$ take-off angle was set in all measurements. Curve fitting was carried out using the CasaXPS software, in which each component of the complex envelope is described as a Gaussian-Lorentzian sum function using a constant $\mathrm{G} / \mathrm{L}$ ratio of $0.3 \pm 0.05$. The background was fitted using a nonlinear Shirley model. An aromatic carbon C $1 \mathrm{~s}$ peak at $284.5 \mathrm{eV}$ was used as the reference of the binding energy.

Transmission electron microscopy (TEM) images of the selected samples were recorded using FEI Tecnai G2 equipment fitted with a CCD (Charge-coupled Device) camera for ease and speed of use at the SCAI (Research Support Service Center, University 
of Cordoba, Spain). The resolution of the equipment was around $0.4 \mathrm{~nm}$. Prior to the recording, samples were suspended in ethanol assisted by sonication and followed by deposition on a copper grid.

Catalyst leaching was analyzed by ICP-MS in SCAI of Universidad de Cordoba. The selected samples were transferred to $25 \mathrm{~mL}$ falcon tube and dried in oven to evaporate the organic compounds. Subsequently, $20 \mathrm{~mL} 2 \% \mathrm{HNO}_{3}$ and $0.5 \% \mathrm{HCl}$ aqueous solution was used to digest the solid components. Samples were then immediately analysed in an ICP/MS Perkin Elmer ELAN-DRC-e model equipped with an automatic diluting injecting system and ionisation under Ar plasma followed by quadrupole ion detection with a DRC cell to remove potential interferences.

\section{RESULTS AND DISCUSSION}

In previously reported work on furfural conversion using a $\mathrm{Cu}-\mathrm{Fe}$ catalyst reaction temperature and pressure showed significant effects on conversion and selectivity [19]. In the present study, we first tested the 5\% Pd/MAGSNC at two different temperatures (90 and $150{ }^{\circ} \mathrm{C}$ ). After 120 minutes streaming in continuous flow at $90{ }^{\circ} \mathrm{C}$, the furfural conversion decreased from $>99 \%$ to $c a .41 \%$, while the selectivity also varied strongly, as shown in ¡Error! No se encuentra el origen de la referencia.. Meanwhile, the furfural conversion (95-99 \%) and the product selectivity (74-90\% to FA) maintained relatively stable after streaming for 20 and 120 minutes at $150{ }^{\circ} \mathrm{C}$. Remarkably, the catalytic performance of $5 \% \mathrm{Pd} / \mathrm{MAGSNC}$ was more stable at higher temperature $\left(150{ }^{\circ} \mathrm{C}\right)$. Therefore, the temperature was set as $150^{\circ} \mathrm{C}$ in the following catalytic tests. 
((Figure 1))

Various lab-synthesized and commercial catalysts were tested for the hydrogenation of furfural in identical conditions. Interestingly, the major product in the reaction catalyzed by $10 \% \mathrm{Pd} / \mathrm{C}$ was THFA instead of pentenol in our previous work [9], showing the high impact of the reaction temperature and the WHSV on the product selectivity. The WHSV in the current work was $3.80 \mathrm{~h}^{-1}$ for $2 \% \mathrm{Pd} / \mathrm{SBA}-15,5 \% \mathrm{Pd} / \mathrm{MAGSNC}$ and $10 \% \mathrm{Pd} / \mathrm{C}$, respectively, which is much higher than the corresponding reported WSHV value of, 1.73 $\mathrm{h}^{-1}$ [9]. All the Pd catalysts exhibited high catalytic activity in furfural conversion, except for the $\mathrm{Cu}-\mathrm{Pd} / \mathrm{Al}-\mathrm{SBA}-15$ catalyst, whereas the Pt catalysts were less active (¡Error! No se encuentra el origen de la referencia.a). Apart from the catalytic activity, the Pd catalysts and Pt catalysts also showed difference in the product selectivity. While Pd catalysts supported on SBA-15 or carbon showed higher selectivity to THFA, 5\% Pd/MAGSNC and Pt catalysts were more favorable in the formation of FA. Despite the Pd content, the main difference between 5\% Pd/MAGSNC and 2\% Pd/SBA-15 was the introduction of $\mathrm{Fe}_{2} \mathrm{O}_{3}$ in the synthesis of the corresponding supports, which in turn influences for instance the dispersion of Pd particles on the support. The introduction of pure Fe into Pd catalysts has shown to increase its catalytic activity in hydrogenation of furfural drastically, at least in aqueous phase [25]. Upon furfural adsorption onto the $\mathrm{Pd}$ or $\mathrm{Pt}$ surface $\eta^{2}-(\mathrm{C}-\mathrm{O})$ surface species were formed, where the first $\mathrm{H}$ could attack the carbonyl $\mathrm{O}$, forming hydroxyalkyl surface species which could be subsequently reduced to form furfuryl alcohol $[10,26,27]$. The difference in reaction activity between Pd catalysts and Pt catalysts could probably be attributed to the strong affinity and sorption of $\mathrm{H}_{2}$ on the palladium surface [28]. Besides, 
Pd and Pt nanoparticles also behave differently in the affinity and sorption of furfural. In detail, Pt favors the sorption of $\mathrm{C}=\mathrm{O}$ bonds [29] and has strong electron repulsive interaction between furan ring $\pi$-electrons and metal d-electrons, whereas Pd shows strong affinity to not only $\mathrm{C}=\mathrm{O}$ bonds but also to the furan ring $\pi$-electrons [10,30,31]. Thus, $\mathrm{Pt}$ catalysts shows higher selectivity to FA while Pd catalysts has higher selectivity to THFA.

((Figure 2))

After streaming for 120 minutes (Figure 2b), some of the catalysts maintained high activity for the conversion of furfural but with rather small differences in the product selectivity, including 5\% Pd/MAGSNC, 2\% Pd/SBA-15 and 10\% Pd/C. The sharp drop of conversion for the $0.5 \% \mathrm{Pd} / \mathrm{SBA}-15$ catalyst might be due to Pd leaching during the reaction, but no Pd in the sample was detected in the ICP-MS data (Table 1) which could be resulted from the low Pd content in the collected samples. Although the selectivity of the Pt catalysts remained consistent and high, the conversion of furfural was much lower than the three Pd catalysts mentioned before.

Hence, the experiments were repeated with 5\% Pd/MAGSNC, 2\% Pd/SBA-15 and $10 \% \mathrm{Pd} / \mathrm{C}$ to investigate their long-term stability, with times-on-stream between 480 and 1560 min. (Figure 3). The furfural conversion using 5\% Pd/MAGSNC and 2\% Pd/C was reduced to $c a .50 \%$ after 480 and 600 minutes, respectively, but 5\% Pd/MAGSNC showed higher stability in the selectivity. The conversion with the $10 \% \mathrm{Pd} / \mathrm{C}$ catalyst in turn 
remained over $98 \%$ after streaming for 1560 minutes while the selectivity to THFA decreased from 83 to $64 \%$. It exhibited the highest stability among all the catalysts tested. Notably, lab-synthesized catalysts (5\% Pd/MAGSNC and 2\% Pd/SBA-15) with relatively low Pd content showed strong catalytic activity in the first a few hours as compared with the commercial $10 \% \mathrm{Pd} / \mathrm{C}$, and even outperformed $5 \% \mathrm{Pt} / \mathrm{C}$ in the hydrogenation of furfural.

((Figure 3))

To understand better the reaction mechanism, XPS spectra of the fresh and spent 5\% Pd/MAGSNC and 10\% Pd/C catalysts were recorded. The spectra of Fe2p confirmed the presence of $\mathrm{Fe}^{3+}$ on the catalysts surface before and after reaction (Figure 4a-4b), consistent with the well-preserved magnetic property of the catalysts after long time streaming. This facilitates the separation of 5\% Pd/MAGSNC from celite in order to attempt to reactivate the catalyst. The main peak (5/2 orbital) of Pd3d shifted from $c a$. 337.1 to $335.7 \mathrm{eV}$ (Figure $\mathbf{4 c - 4 d}$ ), indicating the reduction of $\mathrm{Pd}^{2+}$ species on the catalysts surface. This difference could be responsible for the change in catalytic performance of 5\% Pd/MAGSNC during the time-on-stream. Although leaching of Pd also can be expected, the peak intensity in the spectrum of the spent catalyst was very similar as in the fresh catalyst. Elemental analysis could provide more reliable results to confirm any leaching effect. In comparison, the Pd3d spectra of the fresh and spent commercial 10\% $\mathrm{Pd} / \mathrm{C}$ catalysts did not show any peak shift, as the initial catalyst was already in the reduced state $(335.7 \mathrm{eV})$. The intensities of both the $5 / 2$ and $3 / 2$ peaks did decrease with respect to the 
intensities in the fresh catalyst, which indicates leaching of Pd from the carbon support. These results show that the evolution of the Pd oxidation state is the main factor to keep the catalytic activity high. Additionally, TEM micrographs of the 5\% Pd/MAGSNC and $10 \% \mathrm{Pd} / \mathrm{C}$ catalysts (Figure 5) were recorded in which the structures of the catalysts were maintained well after long term stability tests.

((Figure 4))

((Figure 5))

Catalyst leaching is a challenging issue in heterogeneous catalysis, which is difficult to avoid. Likewise, there was slight catalyst leaching in the hydrogenation of fufrfural, though it might not be detected by ICP-MS (Table 1). Continuously leaching of Fe content on 5\% Pd/MAGSNC was observed, which might also contribute to the changes in the catalysts acvtivity because presence of Fe promotes the catalytic activity of Pd [25].

((Table 1))

\section{CONCLUSIONS}

Continuous flow hydrogenation of furfural was performed with both lab-synthesized and commercial catalysts in the current work. Based on previous and present results, the temperature and the weight hourly space velocity (WHSV) were factors that affected the 
furfural furfural conversion and product selectivity drastically. The lab-synthesized catalyst (5\% Pd/MAGSNC) offered comparable performance to the $10 \% \mathrm{Pd} / \mathrm{C}$ within the first few hours. Furthermore, its well-preserved magnetic property offers a simple, efficient method for catalyst recovery from solid solution by applying a magnetic field, which is easier for catalyst reactivation. We do believe that findings in the current work offer a possibility for the valorization of biomass derived platform molecules in continuous flow system with easy recovered catalyst.

\section{ACKNOWLEDGEMENTS}

Rafael Luque gratefully acknowledges Consejeria de Ciencia e Innovacion, Junta de Andalucia for funding project P10-FQM-6711. Funding from Marie Curie Actions under ITN Project Photo4Future (H2020-MSCA-ITN-2014-641861), especially for funding WO Ph.D studies.

\section{REFERENCES}

[1] H.C.J. Godfray, J.R. Beddington, I.R. Crute, L. Haddad, D. Lawrence, J.F. Muir, J. Pretty, S. Robinson, S.M. Thomas, C. Toulmin, Food Security: The Challenge of Feeding 9 Billion People, Science (80-. ). 327 (2010) 812-818. doi:10.1126/science.1185383.

[2] J.-P. Lange, E. van der Heide, J. van Buijtenen, R. Price, Furfural-A Promising Platform for Lignocellulosic Biofuels, ChemSusChem. 5 (2012) 150-166. doi:10.1002/cssc.201100648.

[3] H.E. Hoydonckx, W.M. Van Rhijn, W. Van Rhijn, D.E. De Vos, P.A. Jacobs, H.E. Hoydonckx, W.M. Van Rhijn, W. Van Rhijn, D.E. De Vos, P.A. Jacobs, Furfural 
and Derivatives, in: Ullmann's Encycl. Ind. Chem., Wiley-VCH Verlag GmbH \& Co. KGaA, Weinheim, Germany, 2007. doi:10.1002/14356007.a12_119.pub2.

[4] P. Panagiotopoulou, D.G. Vlachos, Liquid phase catalytic transfer hydrogenation of furfural over a Ru/C catalyst, Appl. Catal. A Gen. 480 (2014) 17-24. doi:10.1016/j.apcata.2014.04.018.

[5] R. V. Sharma, U. Das, R. Sammynaiken, A.K. Dalai, Liquid phase chemoselective catalytic hydrogenation of furfural to furfuryl alcohol, Appl. Catal. A Gen. 454 (2013) 127-136. doi:10.1016/j.apcata.2012.12.010.

[6] M.M. Villaverde, N.M. Bertero, T.F. Garetto, A.J. Marchi, Selective liquid-phase hydrogenation of furfural to furfuryl alcohol over Cu-based catalysts, Catal. Today. 213 (2013) 87-92. doi:10.1016/j.cattod.2013.02.031.

[7] N.S. Biradar, A.A. Hengne, S.N. Birajdar, R. Swami, C. V. Rode, Tailoring the product distribution with batch and continuous process options in catalytic hydrogenation of furfural, Org. Process Res. Dev. 18 (2014) 1434-1442. doi:10.1021/op500196x.

[8] K. Fulajtárova, T. Soták, M. Hronec, I. Vávra, E. Dobročka, M. Omastová, Aqueous phase hydrogenation of furfural to furfuryl alcohol over Pd-Cu catalysts, Appl. Catal. A Gen. 502 (2015) 78-85. doi:10.1016/j.apcata.2015.05.031.

[9] A.J. Garcia-Olmo, A. Yepez, A.M. Balu, A.A. Romero, Y. Li, R. Luque, Insights into the activity, selectivity and stability of heterogeneous catalysts in the continuous flow hydroconversion of furfural, Catal. Sci. Technol. 6 (2016) 4705- 
4711. doi:10.1039/C6CY00249H.

[10] V. Vorotnikov, G. Mpourmpakis, D.G. Vlachos, DFT study of furfural conversion to furan, furfuryl alcohol, and 2-methylfuran on Pd(111), ACS Catal. 2 (2012) 2496-2504. doi:10.1021/cs300395a.

[11] M. Ojeda, A.M. Balu, V. Barrón, A. Pineda, Á.G. Coleto, A.Á. Romero, R. Luque, Solventless mechanochemical synthesis of magnetic functionalized catalytically active mesoporous SBA-15 nanocomposites, J. Mater. Chem. A. 2 (2014) 387. doi:10.1039/c3ta13564k.

[12] J.C. Colmenares, W. Ouyang, M. Ojeda, E. Kuna, O. Chernyayeva, D. Lisovytskiy, S. De, R. Luque, A.M. Balu, Mild ultrasound-assisted synthesis of TiO2 supported on magnetic nanocomposites for selective photo-oxidation of benzyl alcohol, Appl. Catal. B Environ. 183 (2016) 107-112. doi:10.1016/j.apcatb.2015.10.034.

[13] C. Zhang, L. Qiu, F. Ke, Y. Zhu, Y. Yuan, G. Xu, X. Jiang, A novel magnetic recyclable photocatalyst based on a core-shell metal-organic framework Fe3O4@MIL-100(Fe) for the decolorization of methylene blue dye, J. Mater. Chem. A. 1 (2013) 14329. doi:10.1039/c3ta13030d.

[14] M.B. Gawande, P.S. Branco, I.D. Nogueira, C.A.A. Ghumman, N. Bundaleski, A. Santos, O.M.N.D. Teodoro, R. Luque, Catalytic applications of a versatile magnetically separable Fe-Mo (Nanocat-Fe-Mo) nanocatalyst, Green Chem. 15 (2013) 682. doi:10.1039/c3gc36844k. 
[15] J.R. Dodson, E.C. Cooper, A.J. Hunt, A. Matharu, J. Cole, A. Minihan, J.H. Clark, D.J. Macquarrie, Alkali silicates and structured mesoporous silicas from biomass power station wastes: the emergence of bio-MCMs, Green Chem. 15 (2013) 1203. doi:10.1039/c3gc40324f.

[16] J. Liu, X. Peng, W. Sun, Y. Zhao, C. Xia, Magnetically Separable Pd Catalyst for Carbonylative Sonogashira Coupling Reactions for the Synthesis of $\alpha, \beta$-Alkynyl Ketones, Org. Lett. 10 (2008) 3933-3936. doi:10.1021/o1801478y.

[17] H. Wang, Y. Liu, M. Li, H. Huang, H.M. Xu, R.J. Hong, H. Shen, Multifunctional TiO2 nanowires-modified nanoparticles bilayer film for 3D dye-sensitized solar cells, Optoelectron. Adv. Mater. Rapid Commun. 4 (2010) 1166-1169. doi:10.1039/b000000x.

[18] S. Verma, D. Verma, A.K. Sinha, S.L. Jain, Palladium complex immobilized on graphene oxide-magnetic nanoparticle composites for ester synthesis by aerobic oxidative esterification of alcohols, Appl. Catal. A Gen. 489 (2015) 17-23. doi:10.1016/j.apcata.2014.10.004.

[19] K. Yan, J. Liao, X. Wu, X. Xie, A noble-metal free Cu-catalyst derived from hydrotalcite for highly efficient hydrogenation of biomass-derived furfural and levulinic acid, RSC Adv. 3 (2013) 3853. doi:10.1039/c3ra22158j.

[20] B. Jarry, F. Launay, J.P. Nogier, V. Montouillout, L. Gengembre, J.L. Bonardet, Characterisation, acidity and catalytic activity of Ga-SBA-15 materials prepared following different synthesis procedures, Appl. Catal. A Gen. 309 (2006) 177-186. 
doi:10.1016/j.apcata.2006.04.044.

[21] M.J. Gracia, E. Losada, R. Luque, J.M. Campelo, D. Luna, J.M. Marinas, A.A. Romero, Activity of Gallium and Aluminum SBA-15 materials in the FriedelCrafts alkylation of toluene with benzyl chloride and benzyl alcohol, Appl. Catal. A Gen. 349 (2008) 148-155. doi:10.1016/j.apcata.2008.07.023.

[22] A. Yepez, F.L.Y. Lam, A.A. Romero, C.O. Kappe, R. Luque, Continuous flow preparation of iron oxide nanoparticles supported on porous silicates, ChemCatChem. 7 (2015) 276-282. doi:10.1002/cctc.201402802.

[23] A. Pineda, A.M. Balu, J.M. Campelo, A.A. Romero, D. Carmona, F. Balas, J. Santamaria, R. Luque, A dry milling approach for the synthesis of highly active nanoparticles supported on porous materials, ChemSusChem. 4 (2011) 1561-1565. doi:10.1002/cssc.201100265.

[24] M. Ojeda, A. Pineda, A. a. Romero, V. Barrón, R. Luque, Mechanochemical Synthesis of Maghemite/Silica Nanocomposites: Advanced Materials for Aqueous Room-Temperature Catalysis, ChemSusChem. 7 (2014) 1876-1880. doi:10.1002/cssc.201400055.

[25] J. Lee, Y.T. Kim, G.W. Huber, Aqueous-phase hydrogenation and hydrodeoxygenation of biomass-derived oxygenates with bimetallic catalysts, Green Chem. 16 (2014) 708. doi:10.1039/c3gc41071d.

[26] S. Sitthisa, T. Pham, T. Prasomsri, T. Sooknoi, R.G. Mallinson, D.E. Resasco, Conversion of furfural and 2-methylpentanal on $\mathrm{Pd} / \mathrm{SiO} 2$ and $\mathrm{Pd}-\mathrm{Cu} / \mathrm{SiO} 2$ 
catalysts, J. Catal. 280 (2011) 17-27. doi:10.1016/j.jcat.2011.02.006.

[27] B. Liu, L. Cheng, L. Curtiss, J. Greeley, Effects of van der Waals density functional corrections on trends in furfural adsorption and hydrogenation on closepacked transition metal surfaces, Surf. Sci. 622 (2014) 51-59. doi:10.1016/j.susc.2013.12.001.

[28] M. Yamauchi, R. Ikeda, H. Kitagawa, M. Takata, Nanosize Effects on Hydrogen Storage in Palladium, J. Phys. Chem. C. 112 (2008) 3294-3299. doi:10.1021/jp710447j.

[29] F. Delbecq, P. Sautet, A Density Functional Study of Adsorption Structures of Unsaturated Aldehydes on Pt(111): A Key Factor for Hydrogenation Selectivity, J. Catal. 211 (2002) 398-406. doi:10.1006/jcat.2002.3744.

[30] A. Giroir-Fendler, D. Richard, P. Gallezot, Selectivity in Cinnamaldehyde Hydrogenation of Group-VIII Metals Supported on Graphite and Carbon, in: 1988: pp. 171-178. doi:10.1016/S0167-2991(09)60812-0.

[31] S. Bhogeswararao, D. Srinivas, Catalytic conversion of furfural to industrial chemicals over supported Pt and Pd catalysts, J. Catal. 327 (2015) 65-77. doi:10.1016/j.jcat.2015.04.018. 


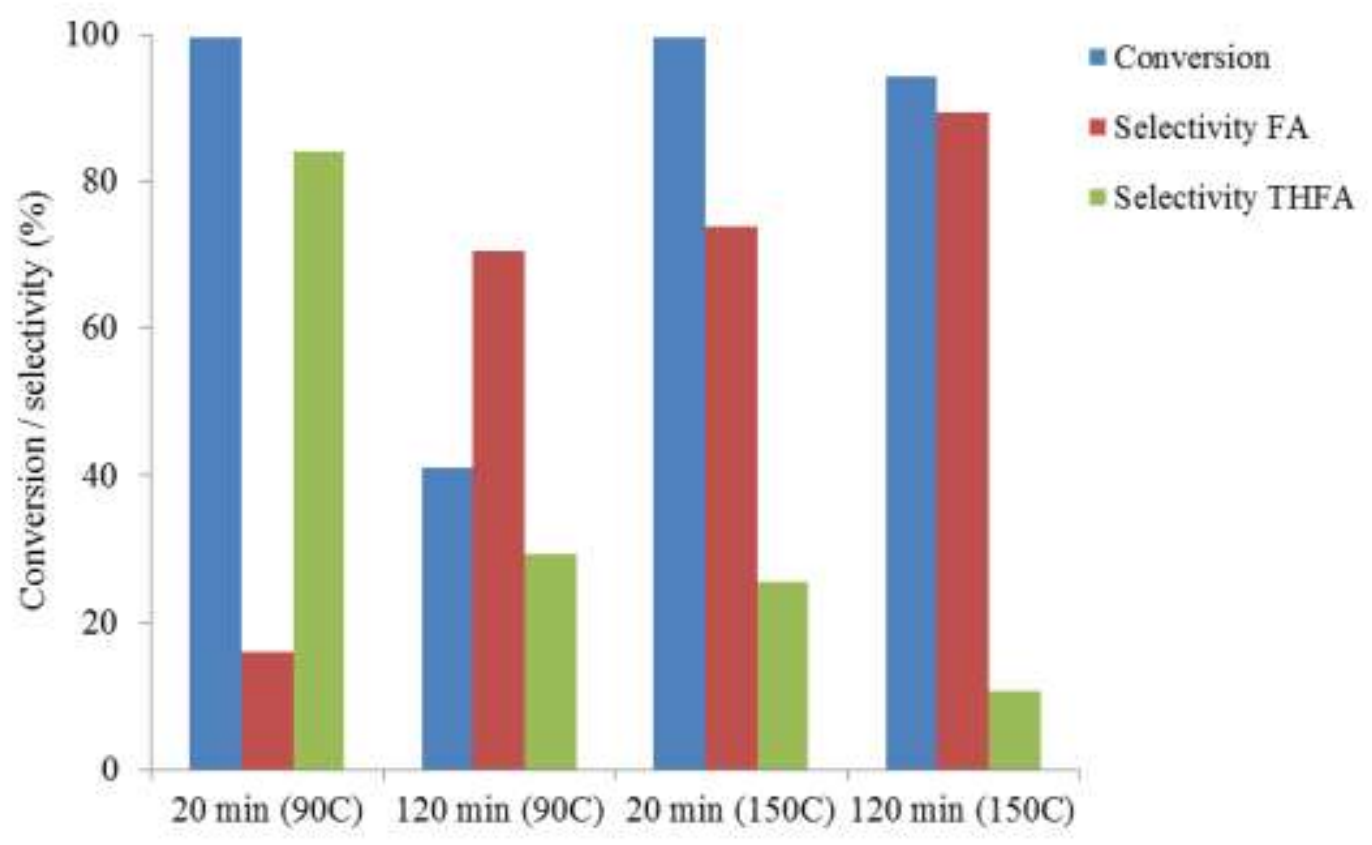

Figure 1. Performance of 5\% Pd/MAGSNC for the conversion of furfural under continuous flow regime in function of time-on-stream and temperature. Reaction conditions: $0.2 \mathrm{M}$ furfural, $0.3 \mathrm{~mL} \mathrm{~min}^{-1}, 50$ bar. 

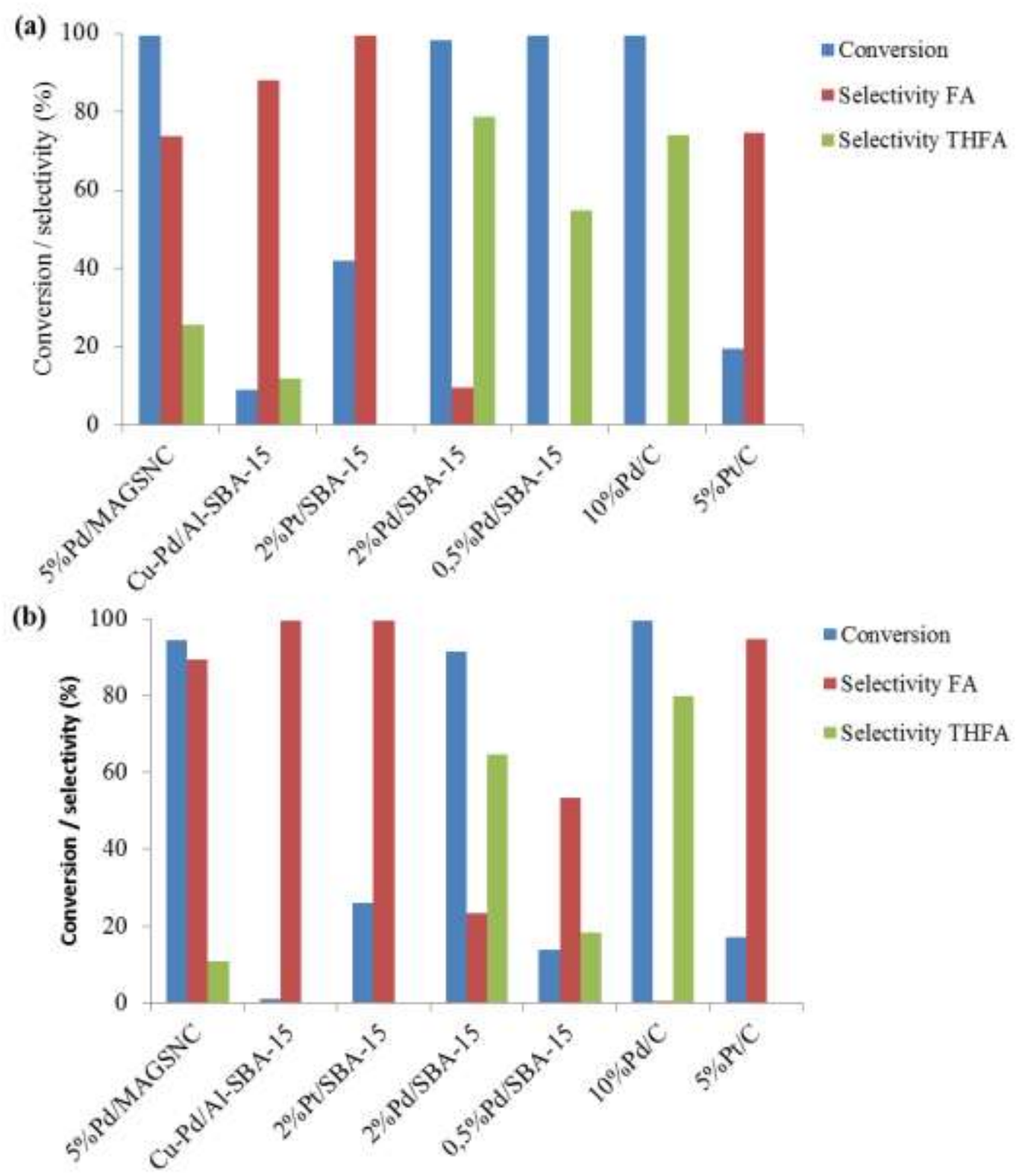

Figure 2. Performance of various $\mathrm{Pd}$ and $\mathrm{Pt}$ catalysts for the conversion of furfural under continuous flow regime after (a) $20 \mathrm{~min}$. time-on-stream and (b) $120 \mathrm{~min}$. time-on-stream. Reaction conditions: $0.2 \mathrm{M}$ furfural, $0.3 \mathrm{~mL} \mathrm{~min}^{-1}$, temperature $=150{ }^{\circ} \mathrm{C}, 50 \mathrm{bar}$. 


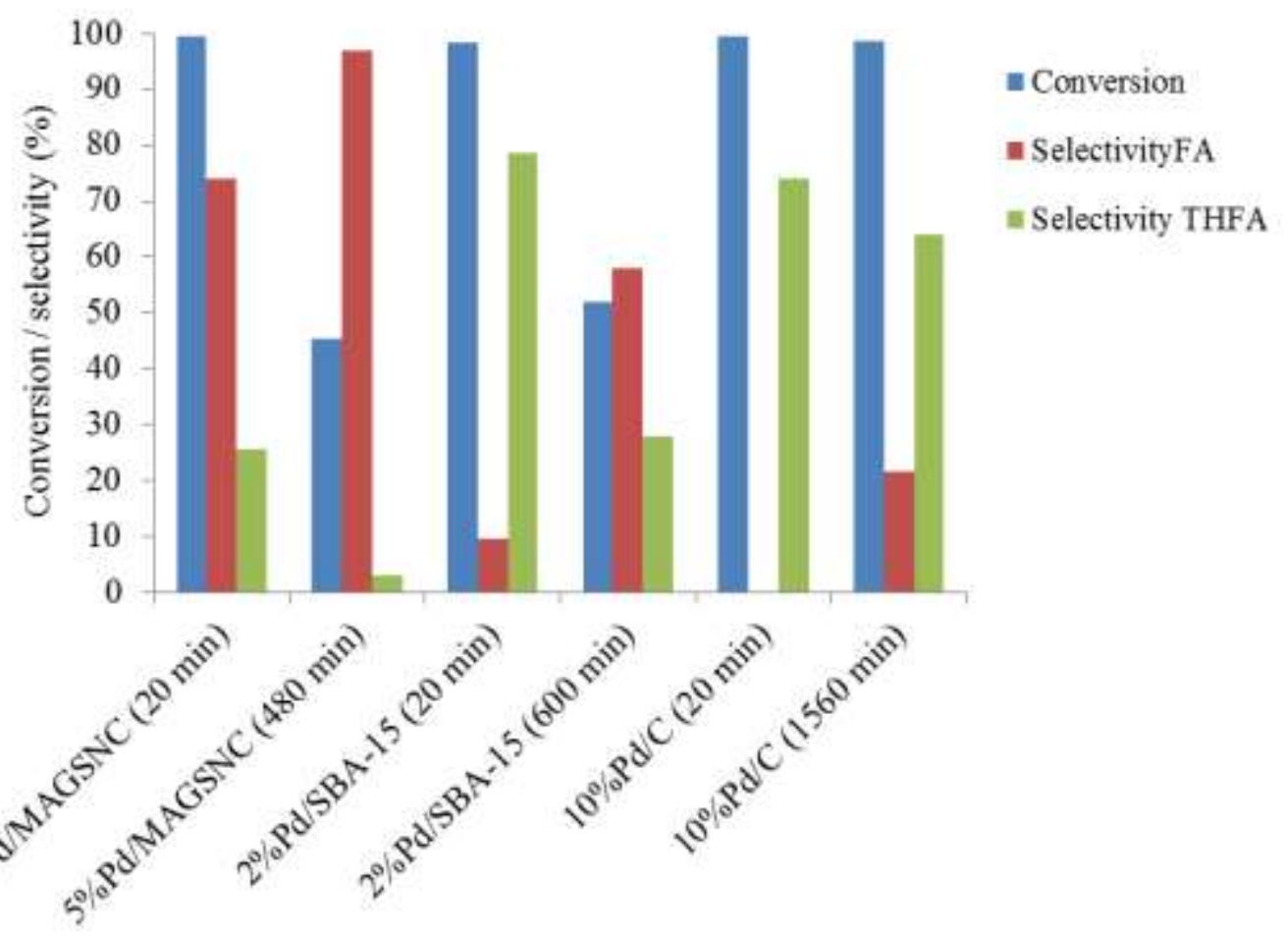

Figure 3. Long term stability of 5\% Pd/MAGSNC, $2 \% \mathrm{Pd} / \mathrm{SBA}-15$ and $10 \% \mathrm{Pd} / \mathrm{C}$ catalysts for the conversion of furfural under continuous flow regime. Reaction conditions: $0.2 \mathrm{M}$ furfural, $0.3 \mathrm{~mL} \mathrm{~min}^{-1}$, temperature $=150{ }^{\circ} \mathrm{C}, 50 \mathrm{bar}$. 

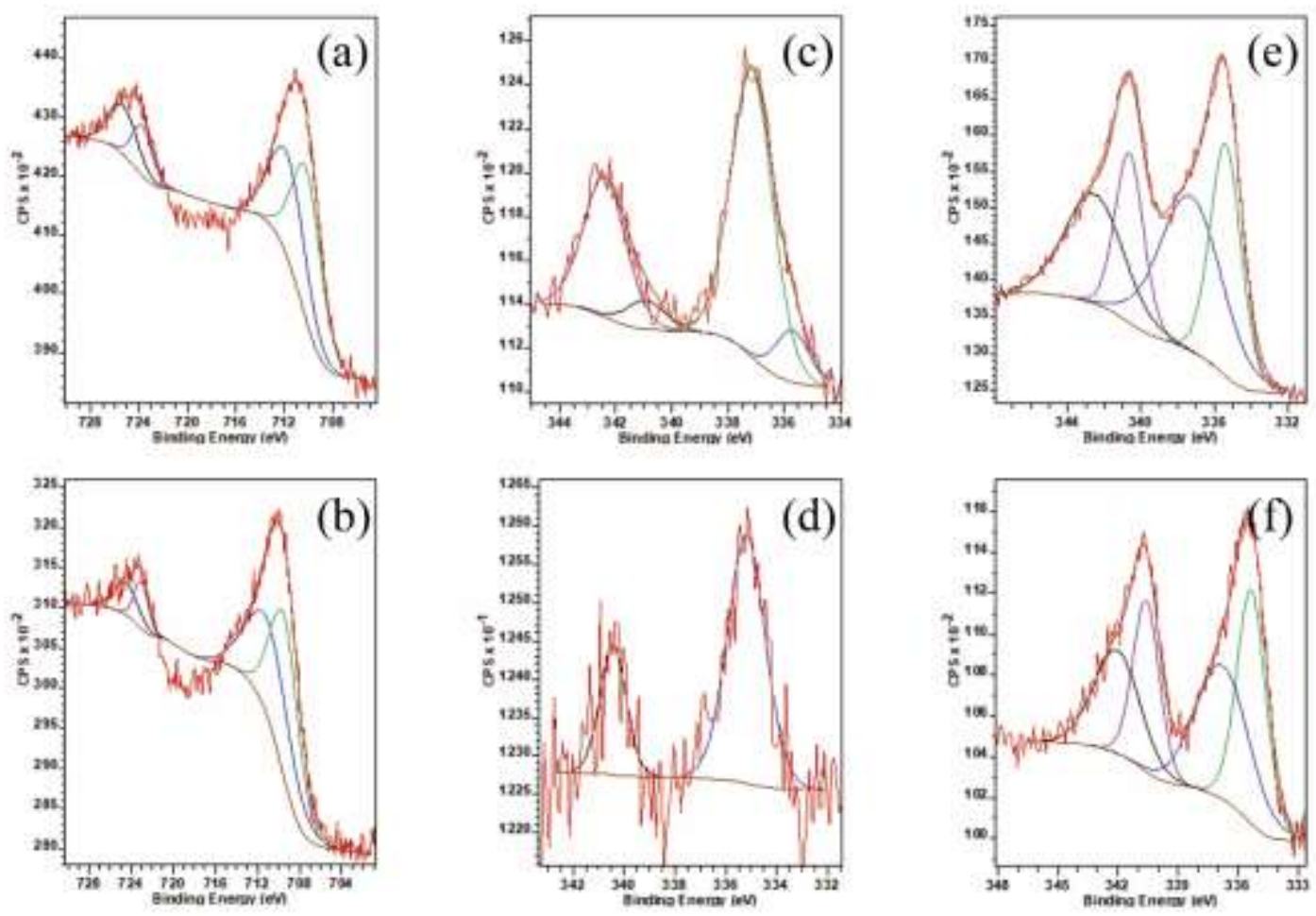

Figure 4. XPS spectra of Fe2p in (a) fresh and (b) spent 5\% Pd/MAGSNC; Pd3d in (c) fresh and (d) spent 5\% Pd/MAGSNC and Pd3d in (e) fresh 10\% Pd/C and (f) spent 10\% $\mathrm{Pd} / \mathrm{C}$. 

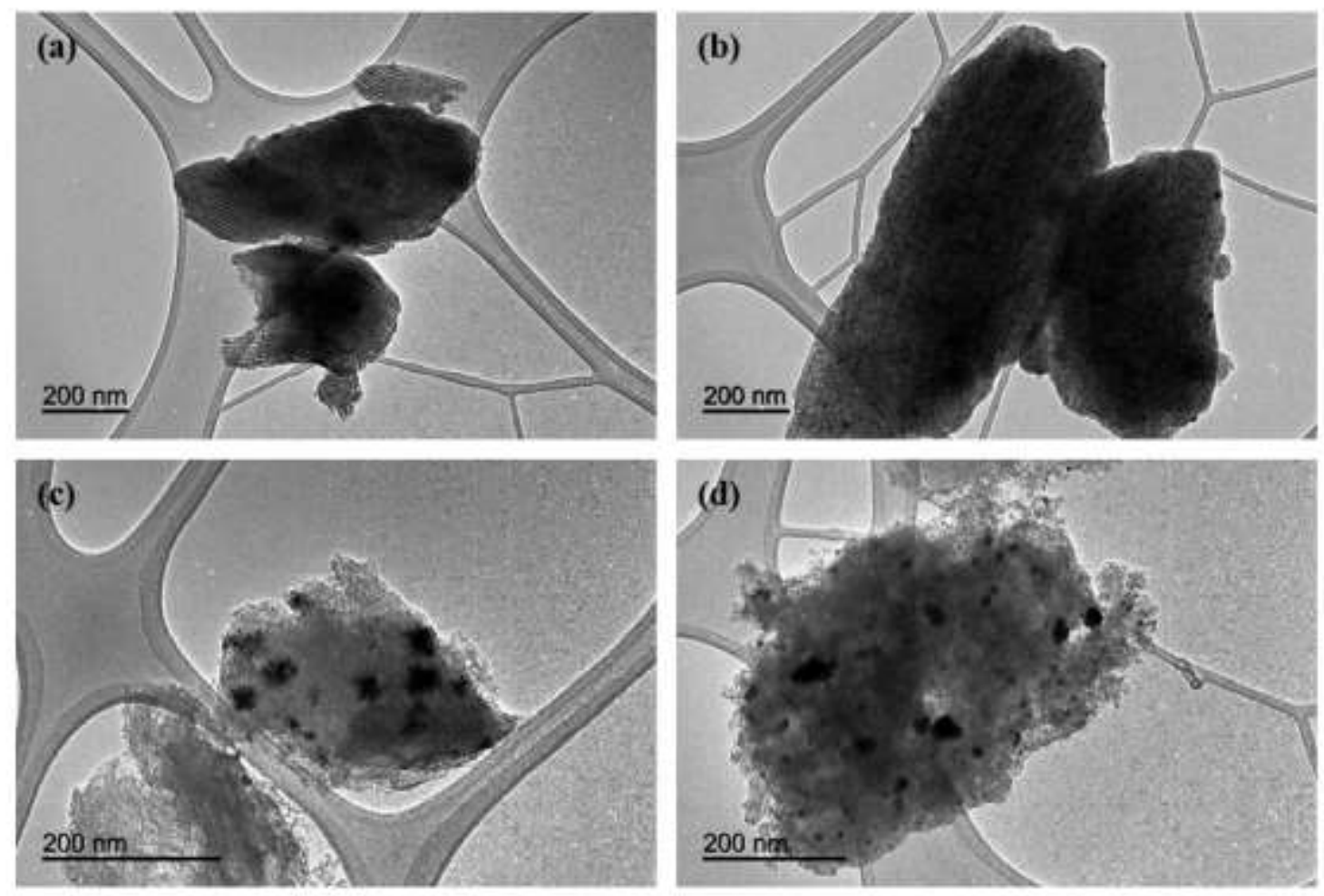

Figure 5. TEM images of (a) fresh and (b) spent 5\% Pd/MAGSNC catalysts, and (c) fresh

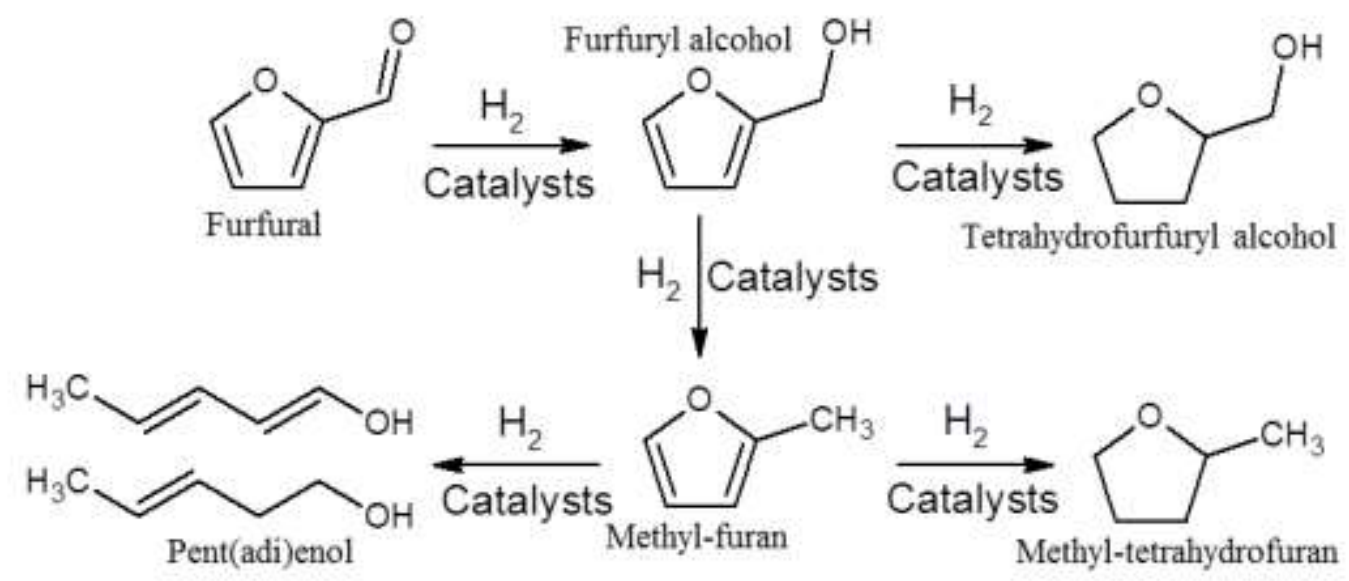

and (d) spent $10 \% \mathrm{Pd} / \mathrm{C}$ catalysts.

Scheme 1. Reaction pathway in the catalytic furfural hydrogenation using heterogeneous catalysts. 
Table 1. Elemental analysis of collected samples using ICP-MS.

\begin{tabular}{ccccccc}
\hline \multirow{2}{*}{$\begin{array}{c}\text { Time-on- } \\
\text { stream (min) }\end{array}$} & \multicolumn{2}{c}{$5 \%$} & \multicolumn{2}{c}{ Element content in the sample $(\mu \mathrm{g} / \mathrm{L})$} & \\
& \multicolumn{2}{c}{ Pd/MAGSNC } & 15 & 15 & $10 \% \mathrm{Pd} / \mathrm{C}$ & $5 \% \mathrm{Pt} / \mathrm{C}$ \\
\cline { 2 - 7 } & $\mathrm{Fe}$ & $\mathrm{Pd}$ & $\mathrm{Pd}$ & $\mathrm{Nd}$ & $\mathrm{Pd}$ & $\mathrm{Pt}$ \\
\hline 20 & 66 & 5 & $\mathrm{ND}^{1}$ & $\mathrm{ND}$ & $\mathrm{ND}$ & $\mathrm{ND}$ \\
120 & 16 & $\mathrm{ND}$ & $\mathrm{ND}$ & $\mathrm{ND}$ & $\mathrm{ND}$ & $\mathrm{ND}$ \\
140 & 13 & $\mathrm{ND}$ & $\mathrm{ND}$ & $/ 2$ & $\mathrm{ND}$ & $\mathrm{ND}$ \\
240 & 44 & $\mathrm{ND}$ & $\mathrm{ND}$ & $/$ & $\mathrm{ND}$ & $\mathrm{ND}$ \\
360 & $/$ & $/$ & 13 & $/$ & $\mathrm{ND}$ & $\mathrm{ND}$ \\
480 & 60 & $\mathrm{ND}$ & $\mathrm{ND}$ & $/$ & $\mathrm{ND}$ & $\mathrm{ND}$ \\
720 & $/$ & $/$ & $\mathrm{ND}$ & $/$ & $\mathrm{ND}$ & $\mathrm{ND}$ \\
1560 & $/$ & $/$ & $/$ & $/$ & $\mathrm{ND}$ & $/$ \\
\hline
\end{tabular}

${ }^{1} \mathrm{ND}$ represents not detected

2 “/” represents no sample 